\title{
O Método Montessori na formação do currículo para o Ensino de Ciências na Educação Infantil
}

\author{
The Montessori Method in formating the curriculum for Science \\ Teaching in Childhood Education
}

\section{El Método Montessori en la formación del currículo de Enseñanza de las Ciencias en la Educación Infantil}

Laura Menezes Eskasinki Dummer ${ }^{1}$; Viviane Castro Camozzato²

\section{RESUMO}

Este artigo aborda a elaboração do currículo para Educação Infantil, que é considerado como um processo complexo que abrange diversos aspectos que vem desde o sistema social até o aluno, sobretudo após a homologação da Base Nacional Comum Curricular (BNCC). A pesquisa considera a importância do ensino de Ciências na Educação Infantil, que deve proporcionar conhecimentos e oportunidades de desenvolvimento de capacidades necessárias para compreender o que se passa à sua volta, tomando posição e intervindo em sua realidade. Neste sentido, o trabalho se utiliza de uma pesquisa ação para analisar a metodologia Montessori no desenvolvimento de atividades como alternativa para elaboração de um currículo para Educação Infantil que possibilite o ensino de Ciências nessa etapa da educação básica visando contemplar a BNCC. A coleta e análise de dados após o desenvolvimento de atividades em uma turma de pré-escola de nível I do município de Bagé/RS mostrou que o pilar "Educação Cósmica" de Montessori vem de encontro ao campo de aprendizagem "Espaços, tempos, quantidades, relações e transformações" da BNCC, mostrando que o método é eficiente para trabalhar Ciências nessa etapa da educação.

Palavras-chave: Currículo; Montessori; Educação Infantil; Ciências.

\begin{abstract}
This article addresses the elaboration of the curriculum for Early Childhood Education, which is considered as a complex process that encompasses several aspects that come from the social system to the student, especially after the approval of the National Common Curricular Base (BNCC). The research considers the importance of science education in early childhood education, which should provide knowledge and opportunities for the development of skills necessary to understand what is going on around them, taking a position and intervening in their reality. In this sense, the work uses an action research to analyze the Montessori methodology in the development of activities as an alternative for the elaboration of a curriculum for Early Childhood Education that allows the teaching of Sciences in this stage of basic education aiming to contemplate the BNCC. The collection and analysis of data after the development of activities in a level I preschool class in the municipality of Bagé/RS showed that the Montessori "Cosmic Education" pillar comes against the learning space "Spaces, times, quantities, relations and transformations" of the BNCC, showing that the method is efficient to work Sciences in this stage of education.
\end{abstract}

Keywords: Curriculum; Montessori; Child Education; Sciences.

\footnotetext{
${ }^{1}$ Licenciada em Pedagogia, Mestra em Ensino e professora da Educação Infantil da Prefeitura Municipal de Bagé/RS - Brasil. E-mail: ddummer@gmail.com

2 Professora da Universidade Estadual do Rio Grande do Sul (UERGS), coordena o Grupo de Pesquisa DESLOGOGIAS - Educação, Culturas e Pedagogias (UERGS/CNPq) e pesquisadora do Núcleo de Estudos sobre Currículo, Cultura e Sociedade (NECCSO/UFRGS/CNPq). E-mail: viviane-camozzato@uergs.edu.br
} 


\section{RESUMEN}

Este artículo aborda la elaboración del currículo de Educación Infantil, el cual es considerado como un proceso complejo que engloba varios aspectos que van desde el sistema social al alumno, especialmente luego de la aprobación de la Base Curricular Común Nacional (BNCC). La investigación considera la importancia de la educación científica en la educación infantil, que debe brindar conocimientos y oportunidades para el desarrollo de las habilidades necesarias para comprender lo que sucede a su alrededor, posicionándose e interviniendo en su realidad. En este sentido, el trabajo utiliza una investigación-acción para analizar la metodología Montessori en el desarrollo de actividades como alternativa para la elaboración de un currículo de Educación Infantil que permita la enseñanza de las Ciencias en esta etapa de educación básica con el objetivo de contemplar el BNCC. - La recolección y análisis de datos luego del desarrollo de actividades en una clase de preescolar de nivel I en el municipio de Bagé/RS mostró que el pilar Montessori "Educación Cósmica" se contrapone al espacio de aprendizaje "Espacios, tiempos, cantidades, relaciones y transformaciones" del BNCC, demostrando que el método es eficiente para trabajar las Ciencias en esta etapa de la educación.

Palabras clave: Plan de estudios; Montessori; Educación Infantil; Ciencias.

\section{INTRODUÇÃO}

A Educação Infantil, de acordo com a Lei de Diretrizes e Bases da Educação (LDB), é a primeira etapa da educação básica. Constitui-se como uma fase de grande relevância no desenvolvimento da criança. A LDB destaca o quanto é papel da escola sistematizar e organizar de forma intencional o processo de aprendizagem tendo como instrumentos fundamentais as brincadeiras, vivências e experiências humanas (BRASIL, 1996).

A construção do Currículo para a Educação Infantil tem ganhado nos últimos anos mais mobilização e, consequentemente, mais referências, estudos e reflexões. Isso tem gerado, sobretudo, enormes desafios aos professores e gestores a fim de que se apropriem dos conceitos e noções presentes nos documentos legais, fazendo uma articulação constante entre a teoria e a prática no cotidiano.

Importante destacar que para as Diretrizes Curriculares Nacionais da Educação Infantil (DCNEI) "currículo é o conjunto sistematizado de práticas culturais no qual se articulam as experiências e saberes das crianças", de suas famílias, dos profissionais e de suas comunidades de pertencimento e os conhecimentos que fazem parte do patrimônio cultural, artístico, científico e tecnológico (BRASIL, 2010, p. 12).

Por sua vez, para o Referencial Curricular Nacional da Educação Infantil (RCNEI) "a interação com adultos e crianças de diferentes idades, as brincadeiras nas suas mais diferentes formas, a exploração do espaço, o contato com a natureza, se constituem em experiências para o desenvolvimento e aprendizagem infantis" (BRASIL, 1998, p. 178). O documento afirma, também, "que o trabalho com os conhecimentos derivados das Ciências Humanas e Naturais deve ser voltado para a ampliação das experiências das crianças e para a construção de conhecimentos diversificados sobre o meio social e natural" (BRASIL, 1998, p. 166).

Os documentos norteadores da Educação Infantil trazem a importância do ensino de ciência, desde a primeira etapa da Educação Básica, para obterem uma educação de qualidade, contemplando todas as áreas de conhecimento, não desmerecendo nenhuma, até porque uma contempla a outra. 
Um aspecto defendido pela Base Nacional Comum Curricular (BNCC) é de que a Educação Infantil, por meio do papel do educador e da instituição escolar, tem como obrigação propiciar experiências as quais crianças ampliem ainda mais os seus conhecimentos e os torne significativos (BRASIL, 2017).

O método Montessori parte do princípio de que todas as crianças têm a capacidade de aprender através de um processo que deve ser desenvolvido espontaneamente a partir das experiências efetuadas no ambiente, que deve estar organizado para proporcionar a manifestação dos interesses naturais da criança, estimulando a capacidade de aprender e fazendo a experimentação da criança, respeitando fatores como tempo e ritmo, personalidade, liberdade e individualidade dos alunos. Neste sentido, o objetivo deste artigo é avaliar a utilização do método Montessori na elaboração do currículo para o ensino de Ciências na Educação Infantil. Esta pesquisa justifica-se devido à importância da adequação de métodos para elaboração de currículo da Educação Infantil que alcancem os objetivos de aprendizagem e desenvolvimento da BNCC.

Esta pesquisa tem uma abordagem qualitativa e utiliza como metodologia a pesquisa ação, desenvolvendo atividades com alunos de pré-escola de acordo com os pilares da metodologia Montessori e analisando sua eficiência quanto ao desenvolvimento de um currículo que alcance os campos de experiência para Educação Infantil, abordados na nova BNCC. O trabalho traz as práticas e vivências da Educação Infantil, mostrando os desafios quanto ao ensino de Ciências para que se possa abraçar as singularidades de cada aluno, tornando-os sujeitos ativos no processo de construção de sua aprendizagem.

\section{CURRÍCULO E EDUCAÇÃO INFANTIL}

A inclusão da Educação Infantil na Educação Básica, como sua primeira etapa, é o reconhecimento de que a educação começa nos primeiros anos de vida e é essencial para o cumprimento de sua finalidade, afirmada no Art. 22 da LDB, o qual assegura que "a educação básica tem por finalidade desenvolver o educando, assegurar-lhe a formação comum indispensável para o exercício da cidadania e fornecer-Ihes meios para progredir no trabalho e nos estudos posteriores" (BRASIL, 1996, p. 14).

Tendo isso em vista, o Ministério da Educação e Cultura (MEC) elaborou os Referenciais Curriculares Nacionais da Educação Infantil (RCNEI), com o objetivo de oferecer uma base nacional comum para os currículos, apesar de não ser obrigatório. O Conselho Nacional de Educação definiu as Diretrizes Curriculares Nacionais para a Educação Infantil (DCNEI), em 2010, como um instrumento a ser seguido compulsoriamente na construção das propostas pedagógicas e do seu desenvolvimento, aprovadas pelo Conselho Nacional de Educação em 2009 (Parecer CNE/CEB no 20/09 e Resolução CNE/CEB no 05/09), que representam uma valiosa oportunidade para se pensar como e em que direção atuar junto às crianças a partir de determinados parâmetros e como articular o processo de ensino-aprendizagem na Escola Básica. Como destaca Oliveira (2010):

As DCNEI foram elaboradas a partir de ampla escuta a educadores, movimentos sociais, pesquisadores e professores universitários, que expuseram suas preocupações e anseios em relação à Educação Infantil, considerando já haver conhecimento consistente acerca do que pode fundamentar um bom trabalho junto às crianças. Elas destacam a necessidade de estruturar e organizar ações educativas com qualidade, articulada com a valorização do papel dos professores que atuam junto às crianças de 0 a 5 anos. Esses são desafiados a construir propostas pedagógicas que, no cotidiano de creches e pré-escolas, dêem voz às 
crianças e acolham a forma delas significarem o mundo e a si mesmas (OLIVEIRA, 2010, p. 1).

Assim, a definição de currículo defendida nas Diretrizes põe o foco na ação mediadora das escolas de Educação Infantil como articuladora das experiências e saberes dos indivíduos e os conhecimentos que circulam na cultura mais ampla e que despertam o interesse das crianças. Esse conceito inaugura, então, um importante período neste ciclo, que pode de modo inovador avaliar as práticas vivenciadas pelas crianças nas instituições de Educação Infantil (OLIVEIRA, 2010).

Por meio das Diretrizes Curriculares Nacionais para a Educação Infantil vemos que as "práticas pedagógicas que compõem a proposta curricular da devem ter como eixos norteadores as interações e a brincadeira" (BRASIL, 2010, p. 25). Isto porque a infância é a fase das brincadeiras e descobertas, é por intermédio das atividades lúdicas que a criança tem oportunidade de vivenciar situações da vida adulta, assimilar a cultura do meio em que vive e a ela se integrar, adaptando e modificando as condições que o mundo lhe oferece e aprendendo a cooperar e conviver em sociedade.

De acordo com Zabalza (1998) o currículo é o itinerário específico e intencional de uma etapa escolar. A sua função pedagógica é garantir a autonomia formativa e a dignidade científica de cada um dos componentes do sistema educativo. Conforme o autor, um currículo de qualidade requer dois elementos. O elemento inicial seriam as experiências e atividades que partem da história e do mundo cultural já existente das crianças e o segundo não menos importante, são as experiências e atividades que deixam de adotar modelos didáticos pré-prontos, concretos e passam a buscar soluções didáticas flexíveis, condizentes com às necessidades reais dos alunos. Uma inovadora organização curricular deverá abrir mão de um ambiente de silencioso e obediente, para concretizar situações nas quais as crianças se mostrem exploradoras e que sejam reconhecidas como protagonistas, que constroem argumentos no confronto com situações estimulantes. A esse respeito Oliveira (2010) salienta que:

O cotidiano da Educação Infantil, como contextos de vivência, aprendizagem e desenvolvimento, requer a organização de diversos aspectos: os tempos de realização das atividades (ocasião, freqüência, duração), os espaços em que essas atividades transcorrem (o que inclui a estruturação dos espaços internos, externos, de modo a favorecer as interações infantis na exploração que fazem do mundo), os materiais disponíveis e, em especial, as maneiras de o professor exercer seu papel (organizando o ambiente, ouvindo as crianças, respondendoIhes de determinada maneira, oferecendo-Ihes materiais, sugestões, apoio emocional, ou promovendo condições para a ocorrência de valiosas interações e brincadeiras criadas pelas crianças etc.) (OLIVEIRA, 2010, p. 4 - 5).

Para isso, tal instituição necessita seguir alguns princípios e condições indicados pelas Diretrizes, nesse sentido a BNCC vem como um documento normativo com o conjunto das aprendizagens essenciais que os estudantes devem desenvolver ao longo das etapas da Educação Básica.

\subsection{A BNCC e a Educação Infantil}

A BNCC define quais são as aprendizagens essenciais que todos os alunos da educação básica têm o direito de adquirir. Na Educação Infantil ela propõe mudanças, mas não dispensa os documentos oficiais. A Base está alinhada às Diretrizes Curriculares e tem a função de normatizar o funcionamento da Educação Infantil. Ela está orientada pelos "princípios éticos e políticos que visam 
a formação humana em suas múltiplas dimensões e a construção de uma sociedade mais justa, democrática e inclusiva" (BRASIL, 2017, p. 7). De acordo com Aquino e Menezes (2016):

A BNCC, traz uma perspectiva de aprendizagem, desenvolvimento, cuidado e educação que ganham vida própria neste documento, pois como conceitos inerentes aos objetivos educacionais que estão carregados de fixações e afirmam muito mais os seus "pressupostos" do que propriamente as singularidades das/os estudantes, ou melhor dizendo, os sentidos singulares e peculiares que cada menina e cada menino, cada jovem e cada adulto imprimem em suas experiências de aprendizagem e em suas reais condições de desenvolvimento, e que deveriam, de fato, ser constitutivos dos objetivos educacionais (AQUINO; MENEZES, 2016, p. 32).

Para melhor entender as mudanças ocorridas no modo de planejar ou de trabalhar o pedagógico em sala de aula é necessário ter a compreensão e conhecimento de quais competências devem ser alcançados ao longo do ano na Educação Infantil. Nessa direção, a BNCC (BRASIL) nos diz que:

Ao longo da Educação Básica, as aprendizagens essenciais definidas na BNCC devem concorrer para assegurar aos estudantes o desenvolvimento de dez competências gerais, que consubstanciam, no âmbito pedagógico, os direitos de aprendizagem e desenvolvimento (BRASIL, 2017, p. 8).

Conforme destacado anteriormente, pretende-se assegurar aos discentes uma formação íntegra e humana que visa a construção de uma sociedade mais justa, democrática e inclusiva, Nesta primeira etapa da Educação Básica, que é a Educação Infantil, o pilar inicial da trajetória escolar, onde devemos destacar as 10 Competências Gerais da Educação Básica se desdobram em direitos de aprendizagem e desenvolvimento (conviver, brincar, participar, explorar, expressar e conhecer-se) e estabelece 5 campos de experiências ( $\mathrm{O}$ eu, o outro e o nós; Corpo, gestos e movimentos; Traços, sons, cores e formas; Escuta, fala, pensamento e imaginação; Espaços, tempos, quantidades, relações e transformações). Para campo de experiências temos objetivos de aprendizagem que estão organizados em 3 grupos por faixa etária: bebês $(0-1 \mathrm{a} 6 \mathrm{~m})$; crianças bem pequenas (1a7m-3a11m) e crianças pequenas (4a-5a11m) (BRASIL, 2017).

A BNCC na Educação Infantil propicia um momento novo para essa etapa da Educação Básica ao lançar um novo olhar para o atendimento da criança em seu processo de desenvolvimento e aprendizado. Diante da atual realidade o desafio é dominar as leituras sobre este documento, para esses profissionais desta etapa de ensino, terem domínio e a responsabilidade de inovar na forma planejar suas propostas pedagógicas, na mediação e na organização de espaços e com vistas no desenvolvimento integral dos alunos, assim como suas singularidades e os conhecimentos prévios sobre o mundo e sobre si mesmos. A Figura 1 traz os dos Campos de Experiências da BNCC.

A BNCC (2017) traz o ensino de ciências na Educação Infantil em seu campo de experiência "Espaço, tempo, quantidades, relações e transformações", que diz que o ensino de ciências na Educação Infantil:

As crianças demonstram curiosidade sobre o mundo físico (seu próprio corpo, os fenômenos atmosféricos, os animais, as plantas, as transformações da natureza, os diferentes tipos de materiais e as possibilidades de sua manipulação etc.) e o mundo sociocultural (as relações de parentesco e sociais entre as pessoas que conhece; como vivem e em que trabalham essas pessoas; quais suas tradições e seus costumes; a diversidade entre elas etc.). Além disso, nessas experiências e em muitas outras, as crianças também se deparam, frequentemente, com conhecimentos matemáticos (contagem, ordenação, relações entre quantidades, 
dimensões, medidas, comparação de pesos e de comprimentos, avaliação de distâncias, reconhecimento de formas geométricas, conhecimento e reconhecimento de numerais cardinais e ordinais etc.) que igualmente aguçam a curiosidade (BRASIL, 2017, p. 42-43).

Figura 1: Resumo dos Campos de Experiência da BNCC.

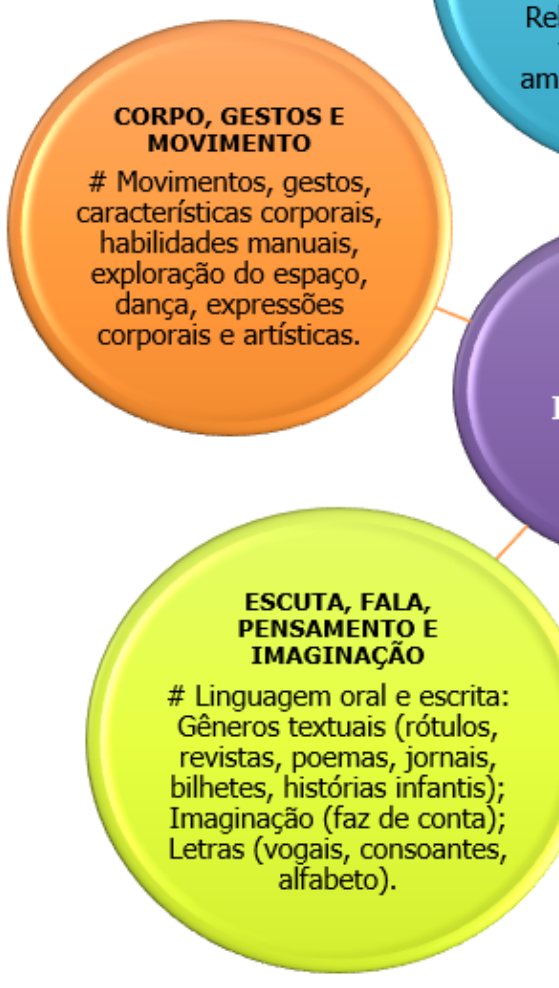

EU, O OUTRO E O NÓs \# Sentimentos, generosidade, diversidade e respeito cultural;

Relação com o outro: família, escola e amizades; Identidade.

Experiências
ESPAÇO, TEMPO,

QUANTIDADES, RELAC̄ÕES

E TRANSFORMAÇÕES

\# Formas geométricas, cores, medidas, classificações, sensações, 0 mundo físico (chuva, natureza, frio), o tempo (dia e noite), agrupamentos e números.

Fonte: Autora (2020)

\subsection{Ensino de Ciências na Educação Infantil}

Conforme Arce et al. (2011), na Educação Infantil o ensino de ciências está relacionado à exploração do mundo real que faz com que a criança o compreenda melhor e também desenvolva habilidades de raciocínio, incentivando assim a imaginação e a criação. Considerando ser o conhecimento científico o resultado do desenvolvimento de ideias, conceitos e teorias, para que ele aconteça é necessário que ocorra a percepção direta do experimento. Os conceitos são assimilados, organizados e relacionados pelas crianças ao longo de suas vivências e experiências.

Segundo Zuquieri (2007), o ensino de ciências, por muito tempo, foi considerado uma atividade pragmática, voltada apenas para os grandes centros educacionais e científicos do mundo. Nem se falava em educação científica para crianças e jovens de países menos desenvolvidos como o Brasil. Conforme problemas ambientais e sociais impostos pela sociedade que se alastram pelo mundo, incorporaram nos currículos escolares valores ao ensino de ciências. Ao acreditar que Ensino de Ciências e sociedade estão ligados por valores e outros aspectos sociais e políticos, os currículos escolares deverão proporcionar não só o ensino da investigação científica, mas, necessariamente, a 
correlação desses aspectos com a cultura, a política, a sociedade e a economia. A esse respeito, Rodrigues (1987) afirma que:

O ensino de ciências deve demonstrar que a ciência é uma das formas de produção da realidade humana, pois, por se contrapor ao saber natural e espontâneo, ela se desenvolve como forma de conhecimento e de domínio da natureza. Esse conhecimento e esse domínio abrem as portas à construção de uma realidade e de um mundo novo na ordem natural. Essa realidade se produz pela incorporação e pela transformação da natureza, de acordo com as necessidades humanas (RODRIGUES, 1987, p. 106).

Divulgar e defender o ensino de ciências é algo encampado por diversos estudiosos nacionais e internacionais, e está sendo realizado de forma a favorecer o conhecimento científico as crianças, estimulando e aguçando o gosto pela investigação podendo sempre construir o aprendizado e novos obstáculos numa busca incessante do seu mundo e do seu imaginário. Nesse sentido Fumagalli (1998) afirma que:

Cada vez que escuto o que as crianças pequenas não podem aprender ciências, entendo que essa afirmação comporta não somente a incompreensão das características psicológicas do pensamento infantil, mas também a desvalorização da criança como sujeito social. Nesse sentido, parece que é esquecido que as crianças não são somente "o futuro" e sim que são "hoje" sujeitos integrantes do corpo social e que, portanto, têm o mesmo direito que os adultos de apropriarse da cultura elaborada pelo conjunto da sociedade para utilizá-la na explicação e na transformação do mundo que a cerca. E apropriar-se da cultura elaborada é apropriar-se também do conhecimento científico, já que este é uma parte constitutiva dessa cultura (FUMAGALLI, 1998, p. 15).

Partindo desse mesmo ponto de vista da autora citada, Rosa et al. (2007, p. 33) "ensinar ciências na Educação Infantil é dotar as crianças de capacidades intelectuais para intervir no mundo. Ou, ao contrário, não abordar conhecimento científico é uma forma de discriminação".

As características intrínsecas encontradas no processo de ensino e aprendizagem de conteúdos de Astronomia a distingue de outras disciplinas, justificando a importância de trabalhar este tema em ambientes escolares como na Educação Infantil (LANGHI; NARDI, 2012).

O ensino de ciências surge como uma oportunidade para proporcionar às crianças espaço para formular suas próprias questões, buscar respostas, imaginar soluções, formular explicações, expressar suas opiniões, interpretações e concepções de mundo, confrontando seu modo de pensar com o de outras crianças e adultos (MIRANDA et al.,2005).

\subsection{0 método Montessori}

Idealizadora do Método, Maria Tecla Artemisia Montessori (1870 - 1952) nasceu em 31 de agosto de 1870 na cidade de Chieravale, na Itália. Primeira mulher a se formar em Medicina em seu país, logo se interessou pelos mecanismos de desenvolvimento do aprendizado infantil.

Albuquerque (2016) afirma que se a ciência estudasse os homens, conseguiria não somente fornecer novas técnicas para a educação das crianças e dos jovens, mas chegaria a uma compreensão profunda de muitos fenômenos humanos e sociais que ainda estão envolvidos em espantosa 
obscuridade. Com o método montessoriano o início de tudo se dá na observação e a experimentação, componentes que fornecem uma base sólida para os primeiros conceitos científicos.

Para Montessori, "liberdade e disciplina se equilibram, e o princípio fundamental é que uma não pode ser conquistada sem a outra. Considerada sob este ângulo, a disciplina não era imposta do exterior, era antes um desafio a ultrapassar para se tornar digno da liberdade". (RÖHRS, 2010, p. 19). As crianças são as protagonistas do próprio desenvolvimento intelectual, emocional e motor, desta forma, Molon (2014), fala sobre os seis pilares educacionais de Montessori:

Autoeducação é a capacidade inata da criança para aprender. Por desejar absorver todo o mundo à sua volta e compreendê-lo, a criança o explora, investiga e pesquisa seguindo os seus interesses;

Educação Cósmica é a melhor forma de auxiliar a criança a compreender o mundo. Estimular sua imaginação e evidenciar que tudo no universo tem sua tarefa e que o ser humano deve ser consciente de seu papel cósmico;

Educação como Ciência é quando o professor utiliza o método científico de observações, hipóteses e teorias para entender a melhor forma de ensinar cada criança e para verificar a eficácia de seu trabalho no dia a dia;

Ambiente Preparado é o local onde a criança desenvolve a autonomia e compreende sua liberdade em escolas e lares montessorianos. O ambiente preparado é construído para a criança, atendendo às suas necessidades biológicas e psicológicas;

Adulto Preparado é o nome que damos, em Montessori, para o profissional que auxilia a criança em seu desenvolvimento completo. Esse adulto deve conhecer cientificamente as fases do desenvolvimento infantil e, por meio da observação e do domínio de ferramentas educativas de eficiência comprovada, guiar a criança em seu desabrochar, de forma que este se dê nas melhores condições possíveis; Criança Equilibrada é qualquer criança em seu desenvolvimento natural. Por meio da utilização correta do ambiente e da ajuda do adulto preparado, as crianças expressam características que lhes são inatas (MOLON, 2014, p. 4 - 5).

Como salienta Röhrs (2010, p. 10-11), "A compreensão mais completa do desenvolvimento permite a utilização dos recursos mais adequados a cada fase e, claro, a cada criança em seu momento, já que as fases não são estanques e nem têm datas exatas para começar e terminar." Desse modo, o método montessoriano, também conhecido como "pedagogia científica" desenvolvido por Maria Montessori [1909] (1965), valoriza e respeita a autonomia e a liberdade da criança. Contudo, a criança necessita de um ambiente preparado com materiais apropriados para trabalho.

Conforme Albuquerque (2016, p. 34), "a educação cósmica é um dos principais legados de Montessori, é multidisciplinar e se constitui no uso de materiais concretos, experiências científicas que apresentam as crianças desde cedo à noção de interdependência".

A educação cósmica difere da educação tradicional, pois tem como objetivo ir muito além da aquisição de conhecimento e do desenvolvimento de uma criança ou de um adolescente, já que respeita as necessidades e os mecanismos evolutivos do desenvolvimento da criança (ALBUQUERQUE, 2016). 


\section{METODOLOGIA}

Esta pesquisa tem uma abordagem qualitativa a adota a investigação do tipo pesquisa-ação, que de acordo com Thiollent (1985), pode ser definida como um tipo de pesquisa com base empírica que é concebida e realizada em estreita associação com uma ação ou ainda, com a resolução de um problema coletivo, em que todos os pesquisadores e participantes estão envolvidos de modo cooperativo e participativo. O cenário de investigação se deu em três turmas de pré-escola de nível 1 de uma escola de Educação Infantil do município de Bagé/RS e envolveu 37 alunos.

\subsection{Coleta de dados}

Visando a busca de dados para a pesquisa foram elaboradas três atividades baseadas no pilar "Educação Cósmica" de Montessori, as quais foram desenvolvidas com os alunos das três turmas envolvidas na pesquisa. A coleta das práticas foi feita de forma audiovisual e as observações e relatos dos alunos registradas em diário de bordo. As atividades trouxeram um convite à experimentação e foram apresentadas na seguinte ordem:

- Atividade 1 (observação do Sol): Estimulação da percepção da forma do Sol com questionamentos iniciais e posteriores observações no pátio e captação de sua forma utilizando o "captador de raios", construído a partir de um rolo de papel toalha;

- Atividade 2 (brincando com sombras): Observação de formas de sombras geradas em pedaços de mármore em diferentes horários;

- Atividade 3 (exploração de materiais): Análise de formas, tamanhos e texturas utilizando retalhos de madeira, pedaços de galhos e recortes de troncos.

\subsection{Análise de dados}

Com os dados coletados foi feita a análise do alcance e da eficiência que cada atividade tem na formação de um currículo para o ensino de Ciências na Educação Infantil. Para essa avaliação foram levados em consideração os seguintes critérios:

- Capacidade de alcançar os objetivos de aprendizagem da BNCC;

- Capacidade de envolvimento dos alunos com materiais não estruturados;

- Capacidade de estimulação do questionamento científico dos alunos.

\section{RESULTADOS}

O professor em sala é um guia (mediador) e, desta forma, busca trazer as vivências dos alunos. As atividades são elaboradas e pensadas, para que as crianças desvendem suas inquietações e achem novos questionamentos enquanto o professor apenas auxilia neste processo.

\subsection{Atividade 1 (observação do Sol)}

O método Montessori é interessante, pois ele parte do interesse da criança, a partir da curiosidade e do conhecimento prévio, o professor tem a missão de planejar o caminho, que elas vão precisar 
caminhar para alcançar suas respostas e estruturar esse conhecimento, com experimentos, pesquisas e etc.

Nesta atividade, ainda em sala de aula, as crianças foram questionadas quanto a forma do Sol. Trouxeram relatos de desenhos animados, revistas e imagens onde viam o Sol com "raios ao redor" ou ainda "uma bolinha com riscos em volta".

Em uma segunda etapa, sentados à sombra no pátio da escola, foram novamente instigados a relatar a forma como viam o Sol e as respostas foram parecidas com as da primeira etapa.

Na última etapa da atividade (Figura 2) os alunos no pátio da escola, em um dia de ensolarado, analisam a forma real do Sol, utilizando um apanhador de raios (um rolo de papel toalha), uma criança de cada vez segurou o sol na palma da mão e pode ver o Sol sem os seus raios. Ficaram encantados em ver que "o Sol é uma bolinha".

Figura 2: Apanhador de raios solares

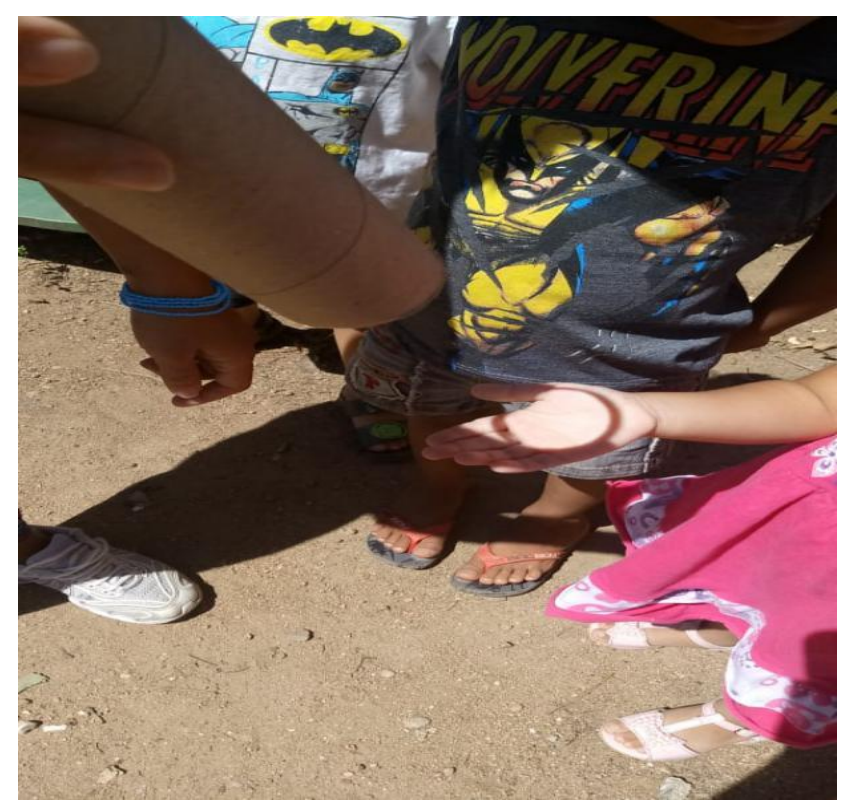

Fonte: Autora (2020)

Segundo Röhrs (2010), ao elaborar materiais didáticos para o ensino das ciências, vislumbrava que cada criança se alfabetizasse científica e ecologicamente por meio do encantamento e de materiais concretos, que a auxiliariam na construção do seu conhecimento de mundo. Isso é exatamente o que ocorre nesta atividade, as crianças mostram-se envolvidas e estimuladas.

Nossos discentes passam inseridos em tempos e espaços de diferentes dimensões, em um mundo constituído de fenômenos socioculturais e naturais. Quando pequenas, elas procuram inserir-se nos mais diversos tempos (dia e noite; hoje, ontem e amanhã etc.) e espaços (rua, bairro, cidade etc.). De acordo com a BNCC (2017):

A Educação Infantil necessita propiciar novas experiências nas quais os discentes possam fazer observações, manipular objetos, investigar e explorar seu entorno, construindo hipóteses e pesquisar fontes de informação para buscar respostas às suas indagações e curiosidades. Contudo, a instituição escolar está criando oportunidades para que as crianças ampliem seus conhecimentos do mundo físico e sociocultural e possam utilizá-los em seu dia a dia (BRASIL, 2017, p. 43). 
Nessa atividade há uma articulação com o campo de experiência da BNCC "Espaço, tempo, quantidades, relações e transformações", posto que desafia os pequenos a pesquisar e a vivenciar com o mundo exterior, pessoas, objetos, materiais não-estruturados de forma a enriquecer 0 repertório do conhecimento dos mesmos, uma vez que aborda questões do cotidiano da criança, como aspectos naturais, físicos, sociais e culturais, podendo assim, ter bastante significado para essas crianças.

\subsection{Atividade 2 (brincando com sombras)}

O planejamento rotineiro da turma de pré I prevê atividades livres diariamente, procurando alternar os ambientes para essas práticas, entre sala de aula, pátio da escola e pracinha. Essa rotina é estruturada para que os princípios do método Montessori funcionem em harmonia, para que a criança se desenvolva de forma completa e equilibrada. É preciso compreender a criança para identificar nela os sinais da eficiência daquilo que lhe está sendo oferecido.

A Figura 3 traz atividades de sala de aula, onde as crianças usam pedaços de mármore como materiais não-estruturados, para desenvolver atividade de observação da sombra, relacionando-a a posição solar, em diferentes horários. O grupo começou a fazer alguns questionamentos sobre a sombra das pedras: por que a sombra desta pedra é para esse lado? Se eu sentar aqui ela não tem sombra? Por que na hora da saída a sobra da pedra tá mais comprida? Isso mostra o interesse e envolvimento das crianças e que podemos pesquisar a partir das inquietações deles.

Figura 3: Brincando com sombras

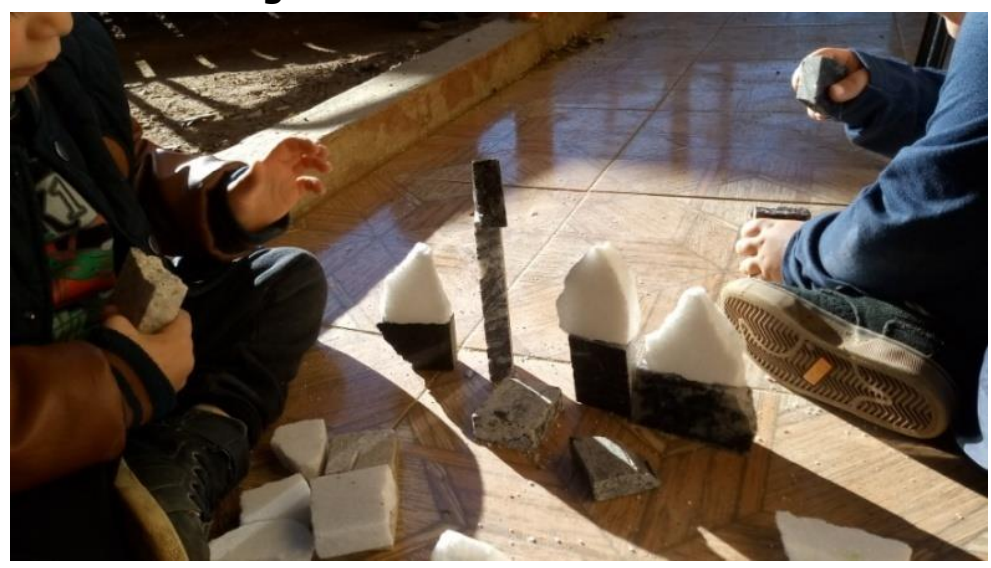

Fonte: Autora (2020)

Conforme Rosa et al. (2007), o importante é que a criança tenha oportunidades de estabelecer contato com as manifestações dos fenômenos naturais, de experimentar, testar hipóteses, questionar, expor suas ideias e confrontá-las com as de outros, enfim, de vivenciar experiências novas e estar em contato com o mundo científico.

A BNCC (2017, p. 44) afirma que "é preciso promover experiências nas quais as crianças possam fazer observações, manipular objetos, investigar e explorar seu entorno, levantar hipóteses e consultar fontes de informação para buscar respostas às suas curiosidades e indagações". A atividade 2 proporciona essas experiências, criando oportunidades para que as crianças ampliem seus conhecimentos do mundo físico e sociocultural e possam utilizá-los em seu cotidiano. 


\subsection{Atividade 3 (exploração de materiais)}

Montessori [1909] (1965) destaca no seu método aplicado para o ensino de ciências, a exploração livre de materiais, como árvores, as flores e os animais. Na Figura 4 vemos a proposta de atividade de investigar as formas, tamanhos e pesos e texturas utilizando retalhos de madeira, galhos e troncos de árvores, onde puderam explorar que alguns eram mais lisos enquanto outros tinham casca áspera ou tinham a casca bem grossa e também que alguns eram curtos comparados a outros mais compridos. Exploraram também recortes de madeiras, com a liberdade de criar, testar e reinventar possibilidades de brincadeiras, ao mesmo tempo que empilham as peças, começam a perceber 0 equilíbrio, noções de espaço, se a outra peça encaixa ou fica grande demais, são questionamentos e aprendizados e trocas de experiências com os outros colegas.

Figura 4: Explorando materiais

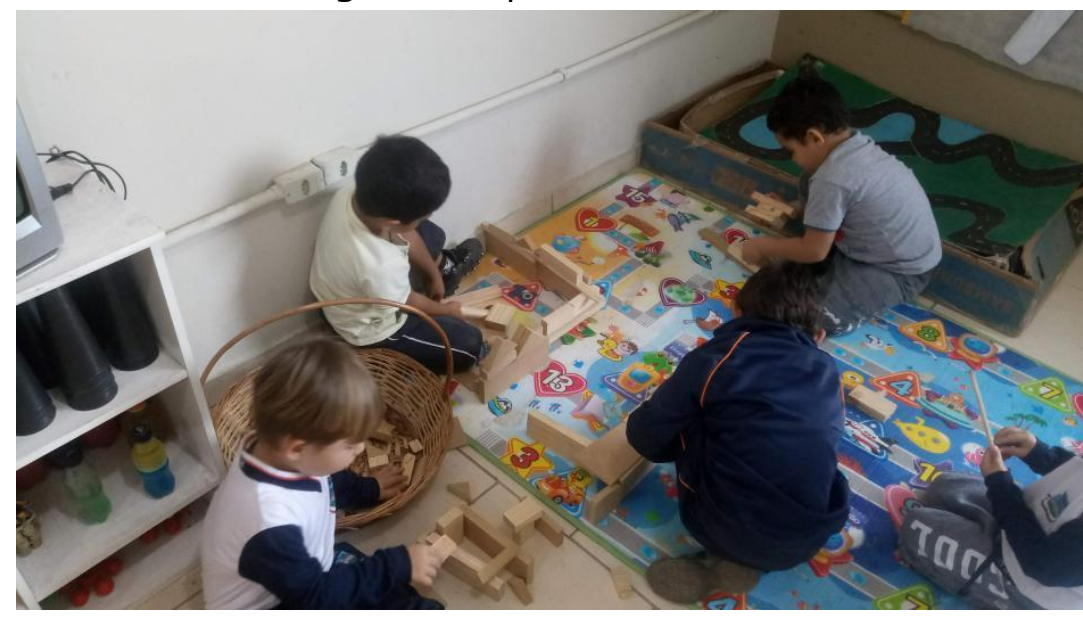

Fonte: Autora (2020)

A atividade 3 trouxe algumas das aprendizagens citada pela BNCC: "Utilizar vocabulário relativo às noções de grandeza (maior, menor, igual etc.), espaço (dentro e fora) e medidas (comprido, curto, grosso, fino) como meio de comunicação de suas experiências" (BRASIL, 2017, p. 55).

Essas atividades mostraram uma melhor forma de auxiliar a criança a compreender o mundo aliando a educação cósmica de Montessori ao objetivo de aprendizagem e desenvolvimento da BNCC (2017, p. 51) ao focar em "Observar e descrever mudanças em diferentes materiais, resultantes de ações sobre eles, em experimentos envolvendo fenômenos naturais e artificiais". As crianças têm seus próprios conhecimentos prévios oriundos de sua família e cultura. O papel da escola é proporcionar novas vivências e experiências que propiciem uma aprendizagem autônoma, e que a partir de suas descobertas e socializações, possam tecer os significados e concretizar seus aprenderes com atividades que explorem sua imaginação e curiosidade.

Deste ponto de vista, o método Montessori, com seu pilar da educação cósmica, pode ser um objeto estimulador e reflexivo sobre o método pedagógico utilizado para ensinar Ciências, uma vez que tem como propósito contribuir com a realização de aulas mais divertidas, lúdicas, voltadas para a pesquisa, observação, experiência e autonomia do sujeito, contribuindo, assim, com a elaboração de um currículo para educação infantil que atenda a BNCC no que tange o campo de experiência "Espaços, tempos, quantidades, relações e transformações". 


\section{CONSIDERAÇÕES FINAIS}

Conforme Oliveira (2010), as experiências vividas no espaço de Educação Infantil devem possibilitar o encontro de explicações pela criança sobre o que ocorre à sua volta e consigo mesma enquanto desenvolvem formas de sentir, pensar e solucionar problemas. No processo de formação do currículo é preciso considerar que as crianças necessitam envolver-se com diferentes linguagens e valorizar o lúdico, as brincadeiras, as culturas infantis. Não se trata assim de transmitir à criança uma cultura considerada pronta, mas de oferecer condições para ela se apropriar de determinadas aprendizagens que Ihe promovem o desenvolvimento de formas de agir, sentir e pensar que são marcantes em um momento histórico.

A principal contribuição e o diferencial de Maria Montessori para a educação estão no fato dela defender que as crianças trazem dentro de si o potencial criador que permite a elas mesmas transformar o seu processo de aprendizado e encontrar seu lugar no mundo. Ou seja, uma responsabilidade compartilhada, entre professor e aluno, pelo processo de ensino e aprendizagem. Nesse sentido, compete à escola e ao professor, criarem o ambiente e as condições necessárias para que isso aconteça.

Ter a preocupação que planejar as atividades voltadas para o aluno, muitas vezes acaba nos propiciando um olhar diferenciado para um outro ponto de vista ou até um simples detalhe, que eles querem investigar, como o que acontece muitas com nossos planejamentos em sala de aula, rotineiros, então cabe a nós professores redirecionar o nosso foco e instigá-los sobre o que é interessante para eles.

O ensino de Ciências desde a Educação Infantil permite diferentes explicações sobre o mundo, os fenômenos da natureza e as transformações produzidas pelo homem podem ser expostos e comparados. É espaço de expressão das explicações espontâneas dos alunos e daquelas oriundas de vários sistemas explicativos.

Contrapor e avaliar diferentes explicações favorece o desenvolvimento de postura reflexiva, crítica, questionadora e investigativa, de não aceitação à priori de ideias e informações, possibilita a percepção dos limites de cada modelo explicativo, inclusive dos modelos científicos, colaborando para a construção da autonomia de pensamento e ação.

\section{REFERÊNCIAS}

ALBUQUERQUE, A. C. N. O ensino de ciências na perspectiva da educação montessoriana no $4^{\circ}$ e $5^{\circ}$ ano do ensino fundamental da prima escola Montessori de São Paulo e a instrumentalização deste método na escola municipal Aquilino da Mota. 2016. 92f. Dissertação (Mestrado). Programa de Pós-graduação em Ensino de Ciências, Universidade Estadual de Roraima - UERR, Roraima, 2016. Disponível em: https://uerr.edu.br/ppgec/wpcontent/uploads/2017/08/DISSERTA\%C3\%87\%C3\%830-2016-ANA-CAROLINA-NATTRODTALBUQUERQUE.pdf. Acesso em: 15 jan. 2020.

AQUINO, L. M. L de.; MENEZES, F. M de. Base nacional comum curricular: Tramas e enredos para a infância brasileira. Debates em Educação. Maceió, Vol. 8, no 16, Jul./Dez. p. 29-45 2016.

Disponível em:

https://www.seer.ufal.br/index.php/debateseducacao/article/view/2409/2133.Acesso em: 31 out. 2020. 
ARCE, A; SILVA, D da; VAROTTO, M. Ensinando ciências na educação infantil. São Paulo: Alínea, 2011.

6.1 BRASIL. Lei de Diretrizes e Bases. Lei no 9.394/96, de 20 de dezembro de 1996. Estabelece as diretrizes e bases da educação nacional. Brasília, 1996.

BRASIL. Ministério da Educação e Desporto. Secretaria da Educação Fundamental. Referencial Curricular Nacional para a Educação Infantil. v. 3. Brasília: MEC/SEF, 1998.

BRASIL. Ministério da Educação. Secretaria da Educação Básica. Diretrizes Curriculares Nacionais para a Educação Infantil. Brasília: MEC, 2010.

BRASIL. Ministério da Educação. Base Nacional Comum Curricular. Brasília:MEC, 2017.

BRASIL. Secretaria de Educação Fundamental. Parâmetros Curriculares Nacionais: ciências naturais. Brasília: MEC, 1998.

FUMAGALLI, L. $\mathbf{O}$ ensino de ciências naturais no nível fundamental de educação formal: argumentos a seu favor. In: WEISSMANN, Hilda (Org.). Didática das ciências naturais: contribuições e reflexões. Porto Alegre: ArtMed, 1998. p. 31-56.

LANGHI, R.; NARDI, R. Educação em astronomia. São Paulo: Escrituras, 2012.

MIRANDA, C. R de. S.; PIERSON, A. H. C.; RUFFINO, S. F. Se não vamos "ensinar ciências" por que querer levá-la para a educação infantil? [online] Disponível em :

https://www.google.com/url?sa=t\&rct=j\&q=\&esrc=s\&source=web\&cd=6\&ved=2ahUKEwjppqq35Y TnAhW9CrkGHcL_DScQFjAFegQIBhAC\&url=http\%3A\%2F\%2Fabrapecnet.org.br\%2Fatas_enpec\%2 Fvenpec\%2Fconteudo\%2Fartigos\%2F1\%2Fdoc\%2Fp583.doc\&usg=AOvVaw1jdCQIpasvw6K-TDuntmr. Acessado em: 15 jan. 2020.

MOLON. J. V. Uma releitura do método Montessoriano para o ensino de matemática nos anos finais do ensino fundamental. XVIII EMBRAPEM - Encontro Brasileiro de Estudantes de Pós-graduação em Matemática. Recife-PB, 2014.

MONTESSORI. M. La Scoperta del Bambino. In: Montessori.M. Pedagogia Científica: A Descoberta da Criança. Tradução de Aury Azélio Brunetti. Itália. São Paulo: Flamboyant, 19091965.

RÖHRS, H. Maria Montessori. Coleção Educadores - MEC. Tradução: Danilo di Manno de Almeida, Maria Leila Alves. Recife: Massangana, 2010.

OLIVEIRA, Z de M. R de. O Currículo na Educação Infantil: O que propõem as novas Diretrizes Nacionais? Anais do I Seminário Nacional: Currículo em Movimento - Perspectivas Atuais. Belo Horizonte, 2010.

RODRIGUES, N. Poruma nova escola: o transitório e o permanente na educação. São Paulo: Autores associados/Cortez,1987.

ROSA, C. W.; PEREZ, C. A. S.; DRUM, C. Ensino de física nas séries iniciais: concepções da prática docente. Investigações em Ensino de Ciências, v. 12, n. 3, p.357-368, 2007.

THIOLLENT, M. Metodologia da pesquisa-ação. São Paulo: Cortez, 1985.

ZABALZA, M. A. Qualidade em educação infantil. Porto Alegre: ArtMed, 1998. 
ZUQUIERI, R de. C. B. Ensino de ciências na educação infantil: análise de práticas docentes na abordagem metodológica da pedagogia histórico-crítica. 2007. 201f. Dissertação (Mestrado).

Programa de Pós - graduação em Educação para a Ciência. Universidade Estadual Paulista- UNESP. Bauru. 2007. Disponível em:

https://repositorio.unesp.br/bitstream/handle/11449/90857/zuquieri_rcb_me_bauru.pdf?sequence= 1. Acesso em: 19 out. 2019.

Submissão: 01/12/2020

Aceito: 31/03/2021 